\title{
CHANGES IN RESIDENTIAL, OCCUPATIONAL AND GENDER STRUCTURE OF THE GREATER BANGKOK IN THE GLOBALIZATION PROCESS
}

\author{
Satoshi Nakagawa \\ Graduate School of Economics, Kobe University \\ 2-I Rokkodai-cho, Nada-ku, Kobe, 657-850I, Japan \\ e-mail: nakagawaecon.kobe-u.ac.jp. ac.jp
}

\begin{abstract}
This study investigated recent changes in migration and population structure of the Greater Bangkok considering the impact of economic globalization. The spatial policy of the Thai government has lead newer investments for manufacturing to locate away from Bangkok Metropolis and thereby the industrial structure of Bangkok Metropolis has gradually turned into service-dominated, while the region surrounding Bangkok Metropolis has attracted factories mainly owned by foreign capital. Light industry and electronics industry are concentrated in the adjacent provinces to Bangkok Metropolis and the heavy and petrochemical industry tends to be located in the outer zone of the surrounding region. The service sector and light industry as well as electronics industry prefer female workers and Bangkok metropolis and the adjoining provinces have become female-dominated population structure while male workers tend to gather in the outer zone attracted by heavy and petrochemical industry. It is possible to mention accordingly that the unbalanced spatial distribution of sex structure of population which might cause changes in the norm to the family formation in future is one of the consequences of economic globalization of Thailand, which the investment promotion policy of the government did not assume.
\end{abstract}

Key words: globalization, migration, suburbanization, gender balance, Bangkok

\section{INTRODUCTION}

Since the Plaza Accord in 1985 the Thailand economy has been involved overall in the global economy and the investment of the foreign capital has increased drastically (Figure 1). In accordance to this trend, the Board of Investment, BOI, which is one of the governmental organizations aimed to promote investment into Thailand, reinforced their spatial policy in 1987. The government accepted export-oriented economy and set up so-called free-trade areas in the country. The BOI classified 76 provinces of Thailand into three cate- 
gories of tax incentives (Figure 2). Zone 1 composed by Bangkok Metropolis and five adjoining provinces called Vicinity has least tax incentives aspiring to adjust the excessive concentration to Bangkok. Zone 2 consists of 12 provinces surrounding the Zone 1 except for Phuket Province famous for tourism located in the Southern Region. The rest of 58 provinces are labeled as Zone 3 where maximum tax incentives are provided. This BOl spatial policy has influenced the decision-making of enterprises for their location of investment to a certain extent and therefore recent studies concerning Bangkok and other large metropolises in ASEAN region tend to focus considerably on the urban growth and the location of foreign direct investments stimulated by spatial policy of each government (Guest 1994, 2003, Jones 2002, Jones et al 2000, McGee 1995, McGee and Greenberg 1992). However the studies discussing population changes mention certainly the importance of the foreign direct investment, they do not investigate the relationship between the changing population distribution and the investment concretely and they do not take the demographic consequences of economic globalization. This study thus aims to illustrate the spatial distribution of investment and the population change in Bangkok Metropolitan Region (BMR) and to investigate the impact of economic globalization on the population structure, in particular gender structure of population.

Figure 1: Development of the number of promotional certificates isseued

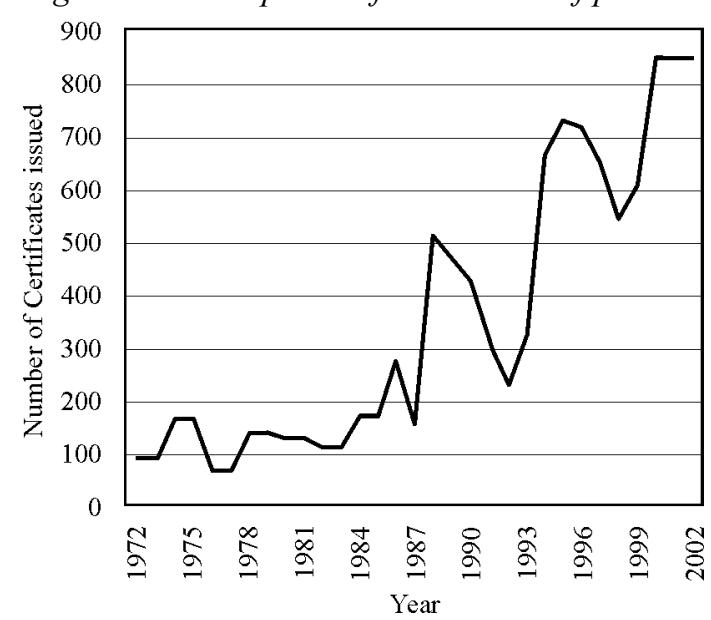

Source: after 1987 Web page of BOI (23 April 2003), before 1986 Thailand in Figures (each year)

\section{SPATIAL DISTRIBUTION OF INVESTMENT}

As mentioned above, The Board of Investment is a key organization for investment in Thailand and most of the enterprises in manufacturing apply for promotional privileges to $\mathrm{BOl}$ when they intend to set up a project for investment in Thailand. BOl provides us database for the projects approved and issued certificates on their homepage, which contain data for more than 10,000 projects concerning name of enterprises, a type of business, date of certi- 
ficates issued for the project, location of factory, location of office, amount of investment, number of Thai and foreign employees and so on, however as far as we know no geographers have made use of this database yet. We thereby try to utilize this database for the investigation of the spatial distribution of investment. Figure 1 is also based mainly on this database.

Figure 2: Thailand classified by thee BOI Zones (2003)

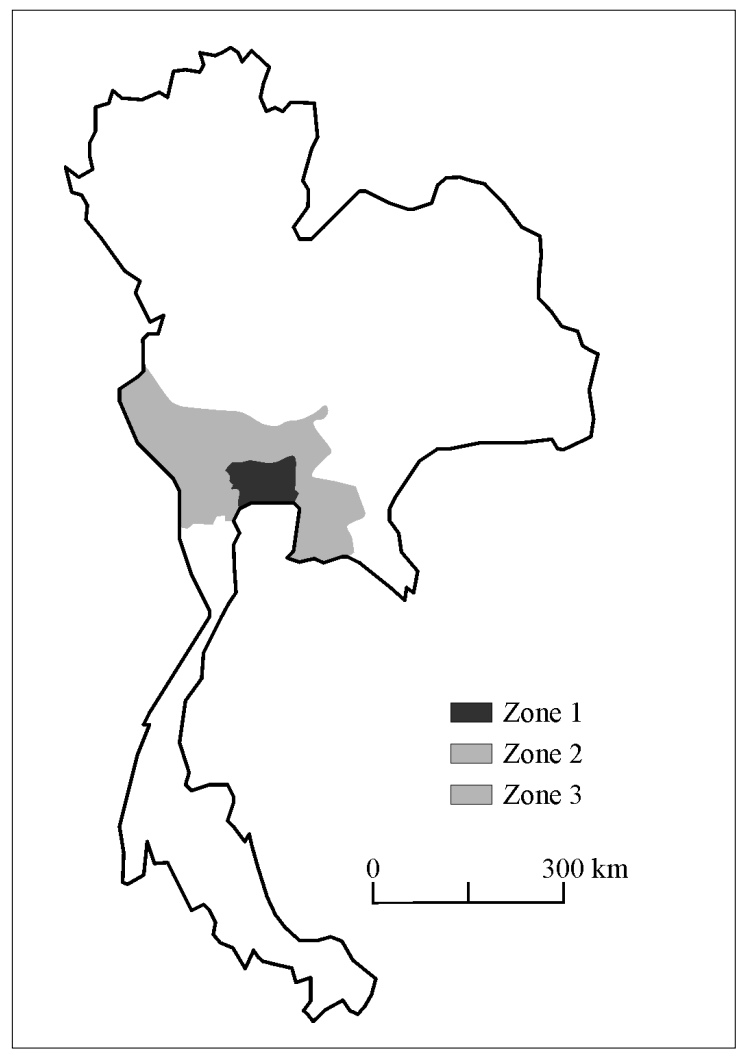

After the reinforcement of the spatial policy in 1987, the distribution of new factories seems to have shifted from Bangkok Metropolis and the vicinity, namely five adjoining provinces, to Zone 2 and Zone 3, which trend is not only for the number of factories, but also true for the amount of investment and numbers of Thai employees. However, the period after 1998, which implies the period after the Asian Monetary Crisis in 1997, the growth of Zone 2 and in particular Zone 3 has weakened, which might be caused by the transfers of investments from Thailand to other countries such as China because of the lower cost of production and slowing down of business in ASEAN countries. Bangkok and the vicinity are dominated by light industry and electronics industry, while general and transport machine industry and chemical industry are concentrated. The Zone 2 area, especially Chon Buri and Rayong Provinces have showed drastic growth in the last decade caused by the 
open of the Laem Chabang Commercial Port in 1991, which should substitute narrow and overloaded Bangkok Port, development of petrochemical complex depending on the natural resources initiated by the government in the along the Eastern Seaboard, and also by the sudden concentration of auto industry after the Asian Monetary Crisis. Now, major auto enterprises intend to set up a large scale assembly factory in Thailand, not for the domestic Thai market, hut rather for the export-oriented to Asian and global markets. These are the reasons why so many transport and chemical industries exist in Zone 2. On the other hand, agricultural and food industry is still popular among Zone 3 provinces however considerable increase of factories is observable in some provinces in Zone 3 neighboring Zone 2 such as Prachin Buri Province.

We also have to pay attention to the location of offices. The crucial condition of the acceptance of the promotional privileges is the location of factories while proximity to governmental institutions and other enterprises and white-collar workers' convenience for commuting are seem to be important factors for the office location. Offices still tend to concentrate in Bangkok Metropolis and its vicinity. This chart is based mainly on the manufacturing industry and the concentration of the service sector in Bangkok Metropolis is naturally much higher than the office distribution.

From the database of the BOl, we could find that the government spatial policy has certainly been effective for the dispersion of factories and employment, at least until the Asian Monetary Crisis, but we also found that when one factory starts operation somewhere in Zone 2 or Zone 3, one or more offices might be also open in Bangkok Metropolis and the wages for factory workers is often lower than the wages for office workers. Therefore, the recent growth of investment has stimulated the increase of employment in the region out of Bangkok, but the disparity of income is still large enough between Bangkok and other regions (Figure 3).

Figure 3: Income per Household by Region

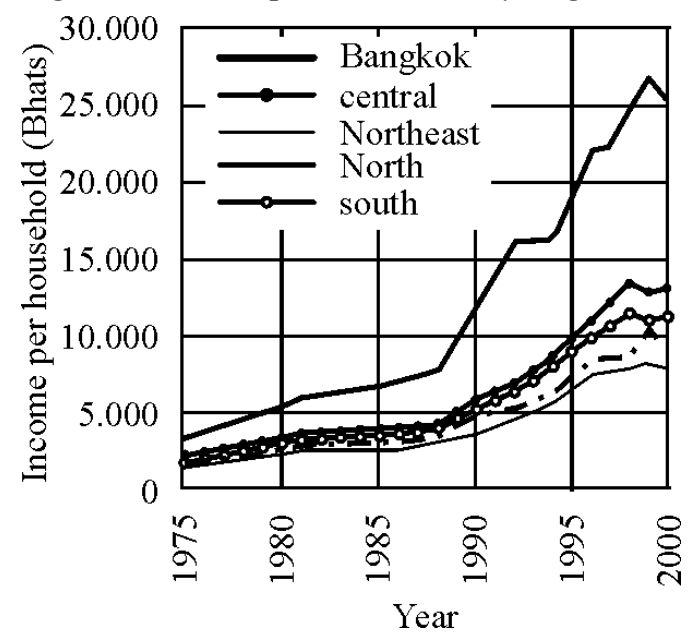

Source: Statistical yearbook of Thailand, each year 
The migration of Thailand by sex and zones for the two periods, 1985-1990 and 19952000. shows that female in-migration to Bangkok Metropolis surpasses the males in size for the both periods, however males outnumber females for the out-migration, which indicates that the sex ratio (male population / female population * 100) of Bangkok Metropolis decreased continuously during the periods. But, the gap of the in- and out-migrants between males and females is getting narrower and absolute number of in-migrants is decreasing recently. On the other hand, the number of migrants, in particular the number of inmigrants, is increasing in the vicinity. The gender balance in migration in this area shows the same trait and the gap is widening and accordingly the living population of this area and is getting female-dominated like Bangkok Metropolis. On the contrary, the Zone 2 is being inclined to dominate male population. Males surpass females in the volume of both in- and out-migration and the difference between males and females is larger in in-migration and thus sex ratio of this zone increases. In addition, Zone 2 showed negative net-migration in 1980s, which implies that this zone still had rural labor-sending characteristics in those days, and turned into a positive net-migration trend first in recent years, which is different from the vicinity. And Zone 3, the rest of Thailand, has labor-sending negative netmigration characteristics and males dominate both in- and out-migration. As shown in Figure 1 and Figure 3, economic growth of Thailand has accelerated for the last decades and regional disparity has been widening. We certainly thereby expect the increase of rural-tourban migration, but the number of out-migrants from Zone 3 does not increase as expected. The reason is probably the decrease of potential migrants in rural regions in recent years derived from the fertility decline in 1970s by the prompt spread of family planning.

The gender balance of each zone indicated by sex ratios, can be regarded as consequences of the above-mentioned migration. The sex ratio of the whole Kingdom is decreasing because of the declining fertility and the aging process. The international outmigration dominated by males may also affect this trend. The regional disparity of gender balance has widened for the last decades, caused by the gender selective migration induced mainly by the labor-oriented foreign direct investment of recent years. Bangkok Metropolis and the vicinity, where service sector, light industry and electronics industry are strongly distributed, are decreasing their sex ratios and intensifying female-dominance among the living population, while Zone 2 characterized by the recent emergence of auto and petrochemical industry tends to become male-dominated population structure.

\section{POPULATION CHANGE}

Now we will deal with population changes of Bangkok as an indicator of urban growth. The outline of population development of Bangkok Metropolis, the vicinity and Zone 2 is shown in Table 1. The substantial limits of urban spatial extension of the mega-cities in ASEAN countries are often pointed out to overcome the administrative boundary and extend radially along the major expressways led mainly by the settling down of foreign direct investment for manufacturing (McGee 1995, McGee and Greenberg 1992, Jones 
2000, Jones et al 2000). We consider the population changes in relation to the extension of urban frontiers. From the Table 1, the population increase of Bangkok Metropolis was intensified in 1970s, was calming down in 1980s, and becomes almost stable in 1990s. On the other hand, the population of the vicinity demonstrates the highest rate of increase in 1980s and 1990s. The Zone 2, pointed out the drastic increase of employment in recent years in the last chapter, does not show substantial population increase even in the last decade. The factories located in this area seem to depend principally on the indigenous rural population otherwise engaging in agriculture. The sum population of the Bangkok Metropolis and the vicinity, this area is often regarded as the Bangkok Metropolitan Region (BMR), is slightly over ten million in 2000 , but the population increase is getting smaller in recent years even including the Zone 2 population.

From this analysis we can conclude that the suburbanization proceeding in and around BMR seems to be calming down. And the suburbanization process in the vicinity, mainly caused by the in-migration of the middle class population from the Bangkok Metropolis in pursuit of better housing condition and by the migration from the rural regions for engaging in the factory work, such as light industry and electronics industry dominated in this area, is somewhat different from that in the Zone 2, where population increase is not so high as expected from the fact that auto industry and petrochemical industry are settling down briskly and the demand of labor force should be large enough in recent years.

Table 1: Population development of Bangkok (1970-2000)

\begin{tabular}{|c|r|r|r|r|r|}
\hline & $\begin{array}{c}\text { Bangkog } \\
\text { Metropolis }\end{array}$ & \multicolumn{1}{c|}{ Vicinity } & $\begin{array}{c}\text { Bangkog Metro- } \\
\text { polis + Vicinity }\end{array}$ & \multicolumn{1}{c|}{ Zone 2 } & \multicolumn{1}{c|}{ Total } \\
\hline Year & population & population & population & population & population \\
\hline 1970 & 3,077 & 1,452 & 4,519 & 4,018 & 8,548 \\
\hline Change & $52,6 \%$ & $34,1 \%$ & $46,7 \%$ & $24,7 \%$ & $6,4 \%$ \\
\hline 1980 & 4,697 & 1,947 & 6,644 & 5,011 & 11,655 \\
\hline Change & $25,2 \%$ & $39,0 \%$ & $29,3 \%$ & $21,3 \%$ & $25,8 \%$ \\
\hline 1990 & 5,882 & 2,707 & 8,590 & 6,076 & 14,666 \\
\hline Change & $8,0 \%$ & $40,5 \%$ & $18,3 \%$ & $12,7 \%$ & $16,0 \%$ \\
\hline 2000 & 6,355 & 3,804 & 10,159 & 6,846 & 17,005 \\
\hline
\end{tabular}

\section{IMPACTS OF GLOBALIZATION - AN ANALYSIS ON SPATIAL GENDER BALANCE-}

Migration is a selective process and mobility often depends considerably on the attributes of individuals such as sex, age, family status and socio-economic status. Although agespecific mobility has been well discussed (e.g. Roger's Model), the difference of mobility by sex or gender and the spatial unbalance of gender caused by such selective migration have not attracted enough attention before. We discuss here the gender-specific migration of Thailand and spatial balance / unbalance of gender. 
We investigate then the declining sex ratio of Bangkok Metropolis in detail. The profile of the sex ratio in 1970 shows us that the in-migrants to Bangkok Metropolis aged 10-19 were dominated by females and thereby the ratio dropped at the age 15-19. There exited export-oriented factories in Bangkok, where female young workers were preferred (Elson 1981). The population aged 25-29 and over weakened their unbalance of sex ratio, which implies that many females go back to their home provinces. The women at that time seemed thereby to stay in Bangkok Metropolis only some years for sending remittance to their parents and to return home for marriage (Osaki 1999). In 1980 and 1990, the concen-tration of the young female population to Bangkok Metropolis became stronger while the return flow of the women to the rural provinces became weaker, which seems to indicate that females' stay in Bangkok is changing from temporally to permanent one and that quite a few rural-born females work in Bangkok even after marriage left their husbands and children back in the rural area or stay single after getting thirty years old. The young female inmigration to Bangkok Metropolis has calmed down to some extent in 2000, and the sex ratio of the population aged 25-49 is significantly lower than before. Females staying longer in Bangkok become obvious. Employers tend to adopt younger females and it is quite difficult to find a less qualified job for women quitted their carrier for marriage or child rearing and more and more women choose to stay single for sending remittance continuously to their family (Mills 1999).

On the other hand, employment structure by industry in Bangkok is changing significantly in recent years. Workers in the manufacturing sector in Bangkok Metropolis started to decrease in 1990s and the vicinity surpassed Bangkok Metropolis in the size of manufacturing workers. Service industry, in particular financial sector, becomes to dominate in Bangkok Metropolis. Many females are also employed in the financial sector and the average age of females in the financial sector is apparently higher than that in the manufacturing. The change of industrial structure also seems to affect lower sex ratio of Bangkok Metropolis.

From the analysis of non-aggregate data from the 2000 population census, the share of single females in Bangkok Metropolis reaches 51\%, 32\% and $24 \%$ for the age group 25$29,30-34$ and 35-39 respectively. The percentage of the single males is much lower. The women with higher educational background and those born in Bangkok tend to stay single in general, and the number of women married but not live together with spouses is quite a large among the rural-born women with less education. It is well known that late marriage is often attributed to the change in the norm of family formation stimulated by higher educational background and and the different gender preferences of employers by industrial sector seem to widen the gap in spatial distribution of gender, which might cause to alter the traditional norm for family formation. This consequence is probably unforeseen by the policy makers.

\section{References}

Elson, D. and Pearson R., 1981:Nimble fingers make cheap workers: an analysis of women's employment in Third World export manufacturing, Feminist Review, 7, 87-107. 
Guest, P., 1994: The impact of population change on the growth of mega-cities, AsiaPacific Population Journal, 9-1, 1994, 37-56.

Guest, P., 2003: Bridging the gap: internal migration in Asia', Paper prepared for Conference on African Migration in Comparative Perspective, Johannesburg, South Africa, 4-7 June, 2003.

Jones, U, 2002: Southwest Asian urbanization and the growth of mega-urban regions, Journal of Population Research, 19-2, 119-136.

Jones, G., Tsay, C-L. and Bajracharya, B., 2000: Demographic and employment change in the mega-cities of South-east and East Asia, Third World Planning Review, 22-2, 119-146.

McGee, T.G, 1995: Metrofitting the emerging Mega-urban regions of ASEAN: an over view, McGee ed. The mega-urban regions of Southeast Asia, UBC Press, 3-26.

McGee, T.G. and Greenberg C., 1999: The emergence of extended metropolitan regions in ASEAN: towards the year 2000, ASEAN Economic Bulletin, 9-1, 1992, 22-44. Mills, M.B., Thai women in the global labor force: consuming desires, contested selves, Rutgers University Press.

Osaki, K., 1999: Economic interactions of migrants and their households of origin, Asian and Pacific Migration Journal, 8-4, 447-472.

Robinson, lra M. 1995: Emerging spatial patterns in ASEAN Mega-urban regions: alternative strategies, McGee ed. The mega-urban regions of Southeast Asia, UBC Press, 78-108. 